\title{
The Influence of Exam Stress on Menstrual Dysfunctions in Saudi Arabia
}

Muneerah Khalid AlJadidi' ${ }^{*}$, Ohoud Oadah AIMutrafi', Rawan Othman Bamousa', Sarah Safar AIShehri', Anwar Sattam AIRashidi', Huda Abdullah AINijadi ${ }^{1}$, Arwa Abdulrhman AMousa ${ }^{1}$, Alanoud Saleh AINami ${ }^{1}$, Norah Mohammad AISubaie ${ }^{1}$, Norah Abdulaziz AlMulhim ${ }^{1}$, and Lamees Abdulla AlAbdulgader ${ }^{1}$

${ }^{1}$ College of Medicine, King Faisal University, Saudi Arabia

${ }^{2}$ Department of Biostatistics, College of Medicine, King Faisal University, Saudi Arabia

\begin{abstract}
Menstrual changes affect the quality of females' lives, it indicates some underlying problems. The purpose of this research is to determine the influence of exams' stress on menstrual dysfunctions. The objectives are to measure the common menstrual dysfunctions among girls during exams, find the most affected characteristics among the measured ones, hence figuring out any relation between the exams (as a source of stress) and the menstrual dysfunctions of 204 Saudi female college students between the age groups of 18 to 25 who matched the required criteria when completed the exam stress social networks questionnaire study on menstrual disorders. It was found that $80.9 \%$ of the sample had menstrual changes during exams. Regarding the characteristics; $59.3 \%$ had a change in the level of pain, $50 \%$ had a change in blood flow, and $54.9 \%$ had it in the menstruation timing. The dysmenorrhea was marked as the most common dysfunction within $57.4 \%$ of the students during exams. A more detailed research is highly required to explore the risk factors, the pathophysiological mechanisms underlying stress in female students during exams in contemplation to establish a modifying or abortive treatment modalities.
\end{abstract}

Keywords: Exam stress; Menstruation; Menstrual changes; Menstrual dysfunctions; Dysmenorrhea

\section{Background}

Adolescence and early adulthood are times of enormous physical and psychological changes for young women. Yet serious gynecological pathologies are rare in these age groups, but menstrual disturbances are not uncommon, it may also add further disruption to this difficult phase in young females' lives and their families'.

Stress is the body's reaction to any change that requires an adjustment or a response. The body reacts to these changes with physical, mental, and emotional responses, exam stress can cause a lot of problems to menstrual disorders and affect it.

\section{Introduction}

There are many women who suffer from menstrual disorders at some point in their life. This problem can significantly affect a woman's life with the exam stress as one of its causes. Stress has always been noted to play a major role as a cause of menstrual disorders.

So, a woman's menstrual cycle might be regular-about the same length every month and her period might be light or heavy, painful or pain-free, long or short, but still be considered normal within a broad range. But as a result of stress that would change to affect the menstruation and take it out from the normal to the abnormal.

\section{Literature Review}

Matteo 1987 showed the effect of job stress and job interdependency on the menstrual cycle length, regularity and synchrony, add to that the effect of the menstrual cycle phases on self-reported measures of daily stress. At the end, the study showed that women who experienced high levels of anxiety and job stress were less synchronized than women with low levels of these variables. As it was shown that longer menstrual cycles were associated with women who reported high levels of anxiety and those who had high scores on the Holmes-Rahe Schedule of Recent Events. Regular cycles were associated with lower levels of anxiety and lower scores on the Holmes-Rahe inventory. Self-reports of daily stress were greater during the late luteal and early menstrual phase of the cycle [1-10].
Harlow and Matanoski showed the association between weight, physical activity, stress and variation in the length of the menstrual cycle. They examined 166 college women, aged 17-19 years, who kept menstrual diaries during their freshman year. At the end it was shown that stressors, characterized by situations, which create a demand for performance or require adjustments to new demands, also increased the risk of a long cycle [2].

Fenster et al. showed the effects of psychological stress in the workplace and menstrual function among married women between 18 and 39 years of age. It was found that women who work in stressful jobs were classified as twice more to experience shorter cycles than those working in other jobs also they were slightly more likely to have an anovulatory episode, but the numbers were very small and the confidence interval included unity. In addition, the effect estimates decreases after adjustment [8].

Barsoma et al. showed the association between psychological stress and menstrual cycle characteristics in premenopausal women. The study population was drawn from participants of the Tremin Research Program on Women's Health (Tremin), a predominantly white, welleducated group of women. The results of this investigation suggested that, in the long term, stressful life events have little relationship to the length of menstrual cycle intervals and the duration of menstrual bleeding in premenopausal women. Though without data on the exact timing of stressful life events, however, these results were not conclusive, especially since there was some indication that marked increases in

${ }^{*}$ Corresponding author: Muneerah Khalid AlJadidi, College of Medicine, King Faisal University, Saudi Arabia, Tel: +00966555808537; E-mail: muneerahkhalid@gmail.com

Received October 12, 2016; Accepted November 07, 2016; Published November 11,2016

Citation: AlJadidi MK, AIMutrafi OO, Bamousa RO, AIShehri SS, AIRashidi AS, et al. (2016) The Influence of Exam Stress on Menstrual Dysfunctions in Saudi Arabia. J Health Educ Res Dev 4: 196. doi: 10.4172/2380-5439.1000196

Copyright: @ 2016 AlJadidi MK, et al. This is an open-access article distributed under the terms of the Creative Commons Attribution License, which permits unrestricted use, distribution, and reproduction in any medium, provided the original author and source are credited. 
the level of stress may be related to the length of cycle intervals and duration of menstrual bleeding in the short term [6].

Allsworth et al. showed the influence of stress on the menstrual cycle among newly incarcerated women. At the end of the study, they were found to have high rates of amenorrhea and menstrual irregularity and the prevalence may be associated with certain stresses. Also, the menstrual dysfunctions were common in this population. $9 \%$ reported amenorrhea, while 33\% reported menstrual irregularities. A number of stressors were associated with menstrual irregularities, including having a parent with a history of alcohol or drug problems, childhood physical or sexual abuse, race/ethnicity, smoking status and recent drug use. These effects were attenuated somewhat when excluding women who had reported with any hormonal contraceptive use in the past 3 months [1].

Sood et al. showed the poor correlation of stress levels and menstrual patterns among medical students. It was done on 359 female medical students from years one and two at the Faculty of Medicine, University Teknologi MARA. All students were between the age groups of 16-20 years with average height and weight and previous normal cycles. The results showed that there is no significant association between stress levels and menstrual changes among preclinical medical students [9].

\section{The Need for the Study}

The study is conducted to determine the effects of exam stress on menstrual disorders on Saudi educated females.

\section{The Objectives of the Study}

$>$ To show the existence of exam stress's effect on menstruation.

$>$ To determine the distribution of exam stress's effect among the characteristics (timing change, flow or pain) of menstruation.

$>$ To measure the frequencies of the most common menstrual dysfunctions during exams.

\section{Methodology}

\section{Research design and sampling}

The sample of the study is designed to include female college students excluding physically less mature ones; those who haven't achieved an ovulatory cycle to have menarche. The study was targeting female sample between age groups of 18-25, single, healthy of any hematological disorders and studying in college.

This research is a descriptive cross-sectional, which consists of a comparison between one group to one subject to determine the most common change (dysfunction) which might be associated with exam stress.

The questionnaire is developed following an extensive review of which questions were more suitable to be asked and would give sufficient answers. Once developed it was reviewed and finalized. The questionnaire included 11 closed questions and 2 open ones. Questions included personal ones, including age, marital status and educational level to exclude undesired samples, others focused on the menstruations of the subjects in relation to the timing, the flow of blood, the level of pain and other characteristics during exams' stressful days. Finally, data have been collected from 204 girls who matched the criteria of the research through an online survey distributed on social networks.

\section{Ethical consideration}

Data was collected anonymously, there was no revealing of any personal information, the questionnaire identified the researchers, their purpose to the respondents, and hence no one but the team was allowed to look through the data.

\section{Statistical analysis}

By using SPSS version 21.0.0,0, data was entered and analyzed using the descriptive statistics (frequencies) and chi-square test of independence to measure the relations.

\section{Results}

A total of 204 girls responded as a match to the criteria of the research questionnaire. All were single college students between the ages of 18-25 years healthy of any hematological diseases.

The Figure 1 shows that 165 girls (80.9\%) had changes in their menstruation during exams, whereas 39 girls (19.1\%) stated no changes.

Table 1 shows that 112 girls (54.9\%) had changes related to the timing of their monthly bleeding onset, whereas 103 girls (50.5\%) had changes related to the menstruation blood flow, 122 girls (59.8\%) had changes related to the level of their menstrual pain and 113 girls (55.4\%) had more than one change in characteristics. This result clearly declares the menstrual pain as the most affected characteristic during exams.

The previously mentioned Table 2 explains how every menstrual characteristic is affected during exams. Out of the 204 girls, it showed that 67 girls (32.8\%) had earlier monthly start, whereas 45 girls (22.1\%) had later monthly start with $0.000 \mathrm{P}$ value $(<0.01)$. Also, the table shows that out of the 204 girls, 61 girls (29.9\%) had their menstrual flow increased (hypermenorrhea), whereas 42 girls (20.6\%) had their menstrual flow decreased (hypermenorrhea) with $0.000 \mathrm{P}$ value $(<0.01)$ It finally shows that 117 girls $(57.4 \%)$ had an increased pain of their menstruation (dysmenorrhea), whereas 5 girls $(2.5 \%)$ had a decreased pain of their menstruation with $0.000 \mathrm{P}$ value $(<0.01)$.

The chi-square test of independence results support that menstrual changes regarding the monthly start, bleeding intensity and menstrual pain do happen during exams.

The Figure 2 showing the percentage of each change arranged from the most common to the least common. It shows that $(57.40 \%)$ has increased in pain (dysmenorrhea), whereas (32.80\%) has an earlier

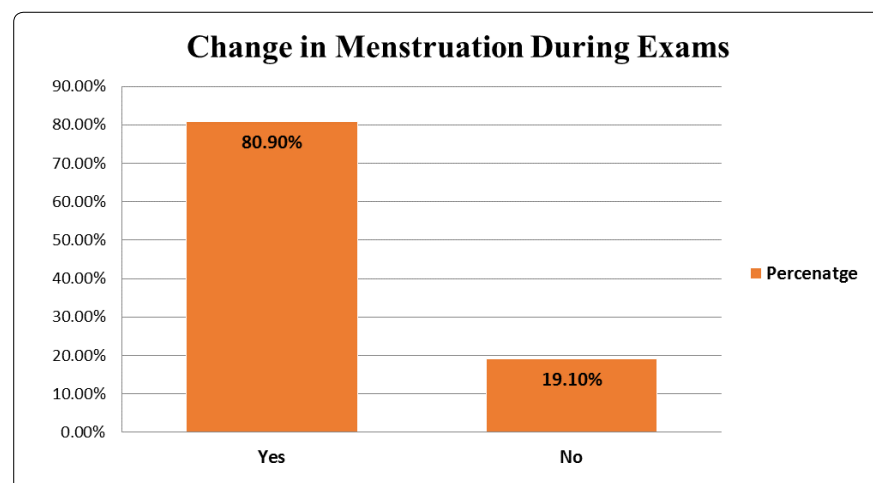

Figure 1: Percentage of prevalence of changes in the menstrual cycle.

\begin{tabular}{|c|c|c|}
\hline Characteristics & Frequency & Percentage \\
\hline Timing change & 112 & $54.9 \%$ \\
\hline Intensity of the flow change & 103 & $50.5 \%$ \\
\hline Change in the level of pain & 122 & $59.8 \%$ \\
\hline Change in several characteristics & 113 & $55.4 \%$ \\
\hline
\end{tabular}

Table 1: Affected characteristics of the menstrual cycle during exams. 
Page 3 of 4

time start, also (29.90\%) had an increase in the flow (hypermenorrhea), (22.10\%) had a late time start, $(20.60 \%)$ had a decrease in flow (hypermenorrhea) whereas (2.5\%) had a low-grade pain.

\section{Discussion}

The first finding in this study is that $80.9 \%$ of our sample has menstrual changes during exams whereas $68 \%$ had more than one change. This finding has been supported by a study which demonstrated a significant association between academic stress and menstrual disorder among undergraduate females as for those who reported high level of academic stress were two times likely to suffer menstrual changes [11]. But it's conflicted with a study that investigated the impact of pre-examination stress in the second year medical students and reported changes in pre-examination menstruation in only $15.91 \%$ of the sample [3]. This difference could be partially due to the fact that the study was measuring different effects of stress and not focusing on the menstruation hence a part of the sample were males.

But why these changes happen is a question that needs to be answered. Some of the theories which might explain what's happening is the physiology of the stress which leads to an increase in cortisol in the body which leads, among others, to the disruption of normal ovulation and menstrual cycle [12] which might be the explanation of the timing change reported by $54 \%$ of the sample (earlier in $32.8 \%$ and later in $22.1 \%)$.

In addition to that, what's worth pointing out is dysmenorrhea, the most common reported dysfunction in $57.4 \%$ of the sample that might be explained by the suggestion that there's a possible neural mechanism through which stress could facilitate pain. This stressinduced hyperalgesia is due to the activation of stress-related circuitry in the hypothalamus to activate pain-facilitating neurons to increase the sensitivity towards pain [12].

\section{Conclusion}

The prevalence of menstrual changes is high among students during exams. The common dysfunctions are: increase in the level of pain (most common), earlier menstruation ( $2^{\text {nd }}$ most common) and an increase in blood flow ( $3^{\text {rd }}$ most common).

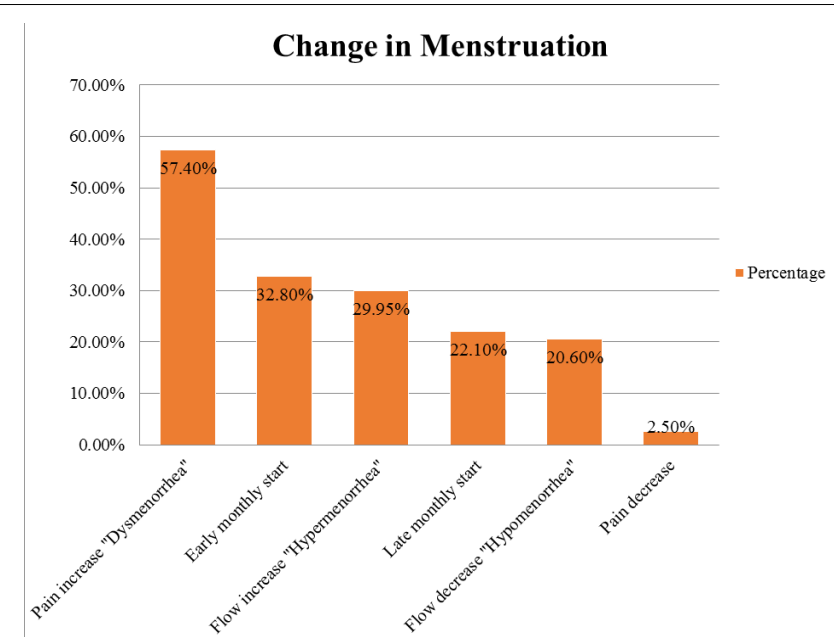

Figure 2: Types of menstrual changes and their percentages.

\begin{tabular}{|c|c|c|c|}
\hline Characteristics & Changes & N (\%) & P Value \\
\hline \multirow{4}{*}{ Date } & On date & $92(45.1 \%)$ & \multirow{4}{*}{$0.000^{* *}$} \\
\hline & Early & $67(32.8 \%)$ & \\
\hline & Late & $45(22.1 \%)$ & \\
\hline & Total & $204(100 \%)$ & \\
\hline \multirow{4}{*}{ Flow } & No change & $101(49.5 \%)$ & \multirow{4}{*}{$0.000^{* *}$} \\
\hline & Increase & $61(29.95 \%)$ & \\
\hline & Decrease & $42(20.6 \%)$ & \\
\hline & Total & $204(100 \%)$ & \\
\hline \multirow{4}{*}{ Pain } & No change & $82(40.2 \%)$ & \multirow{4}{*}{$0.000^{* *}$} \\
\hline & Increase & $117(57.4 \%)$ & \\
\hline & Decrease & $5(2.5 \%)$ & \\
\hline & Total & $204(100 \%)$ & \\
\hline
\end{tabular}

Table 2: Prevalence of changes in menstrual cycle during exams. ${ }^{\mathrm{t}} \mathrm{P}<0.05$; ${ }^{* *} \mathrm{P}<0.01$.

\section{Recommendations}

Based on the results of the research, it's recommend that universities should provide their female students with short courses to teach deep breathing techniques, meditation and yoga as forms of relaxation methods previous to the exams. In addition to offer warm beverages in exam halls to reduce stress and boost students' mood and provide over-the-counter analgesics and warm packs to help with the pain. In addition, there should be a psychosocial specialist to help students succeed academically by providing counseling, instruction, and mentoring for those who are struggling in exams which will benefit students in reducing exams' stress. Lastly, it should be noted that exams are stressful times hence any healthy options for reducing stress should be considered.

\section{References}

1. Allsworth JE, Clarke J, Peipert JF, Hebert MR, Cooper A, et al. (2007) The influence of stress on the menstrual cycle among newly incarcerated women. Women's Health Issues 17: 202-209.

2. Harlow SD, Matanoski GM (1991) The association between weight, physical activity, and stress and variation in the length of the menstrual cycle. American journal of epidemiology 133: 38-49.

3. Rizvi AH, Awaiz M, Ghanghro Z, Jafferi MA, Aziz S (2010) Pre-examination stress in second year medical students in a government college. J Ayub Med Coll Abbottabad 22: 152-55.

4. Begum J, Hossain AM, Nazneen SA (2009) Menstrual pattern and common menstrual disorders among students in Dinajpur Medical College. Dinajpur Med Col J 2: 37-43.

5. Karout N, Hawai SM, Altuwaijri S (2012) Prevalence and pattern of menstrua disorders among Lebanese nursing students. Eastern Mediterranean Health Journal 18: 346-52.

6. Barsom SH, Mansfield PK, Koch PB, Gierach G, West SG (2004) Association between psychological stress and menstrual cycle characteristics in perimenopausal women. Women's Health Issues 14: 235-241.

7. Fenster L, Waller K, Chen J, Hubbard AE, Windham GC, et al. (1999) Psychological stress in the workplace and menstrual function. American Journal of Epidemiology 149: 127-134.

8. Sood M, Devi A, Azlinawati AMD, Razali S, Hapizah Nawawi S, et al. (2012) Poor correlation of stress levels and menstrual patterns among medical students. Journal of Asian Behavioural Studies 2: 59-66.

9. Matteo S (1987) The effect of job stress and job interdependency on menstrual cycle length, regularity and synchrony. Psychoneuroendocrinology 12: 467-476.

10. Ekpenyong CE, Davis KJ, Akpan UP, Daniel NE (2011) Academic stress and menstrual disorders among female undergraduates in Uyo, South Eastern Nigeria - the need for health education. Niger J Physiol Sci 26: 193-198. 
Citation: AlJadidi MK, AIMutrafi OO, Bamousa RO, AIShehri SS, AIRashidi AS, et al. (2016) The Influence of Exam Stress on Menstrual Dysfunctions in Saudi Arabia. J Health Educ Res Dev 4: 196. doi: 10.4172/2380-5439.1000196

Page 4 of 4

11. Aronson D (2009) Cortisol-its role in stress, inflammation, and indications for diet therapy. Today's Dietitian 11: 38 .
12. Martenson ME, Cetas JS, Heinricher MM (2009) A possible neural basis for stress-induced hyperalgesia. Pain 142: 236-244. 